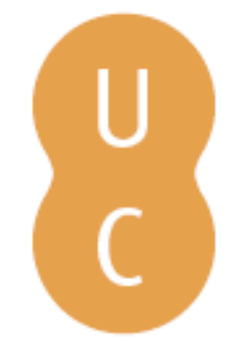

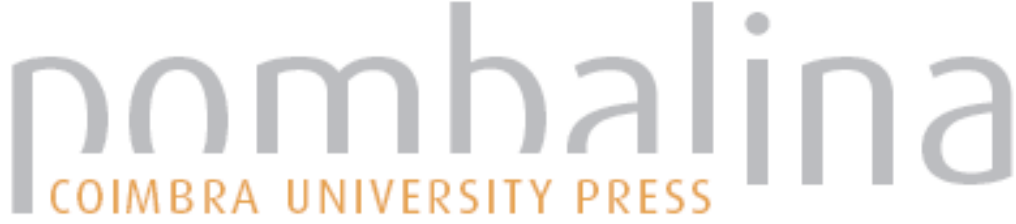

\section{Impacto das drenagens ácidas das minas de Regoufe e Rio de Frades (Geoparque Arouca) na qualidade de água superficial}

\author{
Autor(es): $\quad$ Correia, V. F.; Favas, P. J. C.; Sá, A. \\ Publicado por: Centro de Estudos Clássicos e Humanísticos da Universidade de \\ URL \\ persistente: URI:http://hdl.handle.net/10316.2/31470 \\ DOI: $\quad$ DOI:http://dx.doi.org/10.14195/978-989-26-0534-0_38 \\ Accessed : $\quad$ 26-Apr-2023 13:18:00
}

A navegação consulta e descarregamento dos títulos inseridos nas Bibliotecas Digitais UC Digitalis, UC Pombalina e UC Impactum, pressupõem a aceitação plena e sem reservas dos Termos e Condições de Uso destas Bibliotecas Digitais, disponíveis em https://digitalis.uc.pt/pt-pt/termos.

Conforme exposto nos referidos Termos e Condições de Uso, o descarregamento de títulos de acesso restrito requer uma licença válida de autorização devendo o utilizador aceder ao(s) documento(s) a partir de um endereço de IP da instituição detentora da supramencionada licença.

Ao utilizador é apenas permitido o descarregamento para uso pessoal, pelo que o emprego do(s) título(s) descarregado(s) para outro fim, designadamente comercial, carece de autorização do respetivo autor ou editor da obra.

Na medida em que todas as obras da UC Digitalis se encontram protegidas pelo Código do Direito de Autor e Direitos Conexos e demais legislação aplicável, toda a cópia, parcial ou total, deste documento, nos casos em que é legalmente admitida, deverá conter ou fazer-se acompanhar por este aviso.

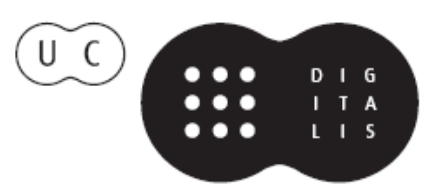





\title{
IMPACTO DAS DRENAGENS ÁCIDAS DAS MINAS DE REGOUFE E RIO DE FRADES (GEOPARQUE AROUCA) NA QUALIDADE DA ÁGUA SUPERFICIAL
}

\author{
IMPACT OF ACID MINE DRAINAGE OF REGOUFE \\ AND RIO DE FRADES MINES (AROUCA GEOPARK) \\ ON SURFACE WATER QUALITY
}

V. F. Correia ${ }^{1}$, P. J. C. Favas ${ }^{2,3} \&$ A. Sá ${ }^{1,2,3}$

Resumo - Foi desenvolvido um estudo hidroquímico nas minas de Regoufe e Rio de Frades visando um conhecimento efetivo do efeito das drenagens ácidas de minas (DAM) na qualidade das águas superficiais desta área. Verificaram-se concentraçóes significativamente elevadas de elementos tóxicos, nomeadamente As (máximo = 236,8 $\mu \mathrm{g} / \mathrm{L}$ ) e Cd $($ máximo $=13,31 \mu \mathrm{g} / \mathrm{L})$, detetados nas drenagens das galerias e escombreiras das minas de Regoufe que, por isso, apresentam um significativo potencial de contaminaçáo hídrica. No couto mineiro de Rio de Frades a situaçáo mais problemática relaciona-se com a existência de depósitos de concentrados de sulfuretos, resultantes da lavaria, expostos às condiçóes atmosféricas e à erosão.

Palavras-chave - Minas abandonadas; Drenagens ácidas de minas; Impactos ambientais; Regoufe; Rio de Frades; Geoparque Arouca (Portugal)

Abstract - A hidrochemical study was developed in the Regoufe and the Rio de Frades tungsten mines for a better knowledge about the effect of acid mine drainage (AMD) on surface water quality in this area. This work shows that the high concentrations of toxic elements, mainly As $($ maximum $=236.8 \mu \mathrm{g} / \mathrm{L})$ and $C d($ maximum $=13.31 \mu \mathrm{g} / \mathrm{L})$, detected in drainage water of the Regoufe abandoned galleries and tailings produces a significant contamination of

\footnotetext{
1 Arouca Geopark, Arouca, Portugal; vcorreia@geoparquearouca.com

2 Dep. de Geologia, Universidade de Trás-os-Montes e Alto Douro, Vila Real, Portugal; pjcf@utad.pt; asa@utad.pt

${ }^{3}$ Centro de Geociências, Universidade de Coimbra, Coimbra, Portugal
} 
this aquatic system. In the Rio de Frades mine the major environmental impact are related with the open air sulphide deposits.

Keywords - Abandoned mines; Acid mine drainage; Environmental impacts; Regoufe; Rio de Frades; Arouca Geopark (Portugal)

\section{1 - Introdução e objetivos}

As antigas explorações mineiras de Regoufe e Rio de Frades, localizadas na área do Geoparque Arouca (distrito de Aveiro), possuem um importante património geológico e mineiro e, por isso, há necessidade de olhar para estas minas como um valor acrescentado, essencial na política de sustentabilidade e desenvolvimento do território.

Este trabalho foca-se no impacto na qualidade da água, do sistema fluvial da área envolvente destas antigas minas de W-Sn, causado pelas drenagens ácidas de minas (DAM) que se originaram no local. Assim, os principais objetivos deste trabalho são: contribuir para o conhecimento da qualidade dos recursos hídricos na área das minas de Regoufe e Rio de Frades; perceber o potencial de contaminação das drenagens ácidas de minas (DAM) que aí se formam e a capacidade autodepuradora do sistema fluvial envolvente; propor medidas de minimização dos impactos identificados.

\section{2 - Enquadramento geológico da área estudada}

A Fig. 1 representa, de forma simplificada, o enquadramento geológico das minas de Regoufe e de Rio de Frades. Estão identificados alguns jazigos de Sn e W relacionados com o batólito granítico de Regoufe, sendo os de maior importância os das minas de Regoufe e Rio de Frades.

Em termos de mineralização, no jazigo de Regoufe a volframite é o minério mais frequente, ocorrendo também alguma cassiterite. Também se identificaram alguns sulfuretos, sendo a arsenopirite o principal, a esfalerite é frequente nos filóes de quartzo, mas a pirite é menos abundante. Encontram-se também outros minerais de menor importância, como a bismutinite, limonite, escorodite, autunite e bindheimite. Entre os minerais silicatados que suportam a mineralização, destaca-se principalmente o quartzo, seguido de alguma moscovite, berilo e apatite (SLUIJK, 1963; FAVAS, 2008).

No que diz respeito ao jazigo de Rio de Frades, a volframite é também identificada como o minério mais abundante, ocorrendo igualmente cassiterite e também alguma scheelite. Tal como no jazigo de Regoufe, a arsenopirite é o principal sulfureto identificado, ocorrendo outros como a pirite, esfalerite pouco abundante, marcassite, pirrotite e estanite e também bismuto nativo. Entre os minerais silicatados que suportam esta mineralização, destaca-se igualmente a presença dominante de quartzo e alguma moscovite e turmalina (SLUIJK, 1963; FAVAS, 2008). As arsenopirites de Regoufe são, em geral, mais ricas em As do que as de Rio de Frades e os valores deste elemento nas pirites também são significativos (FAVAS, 2008). 


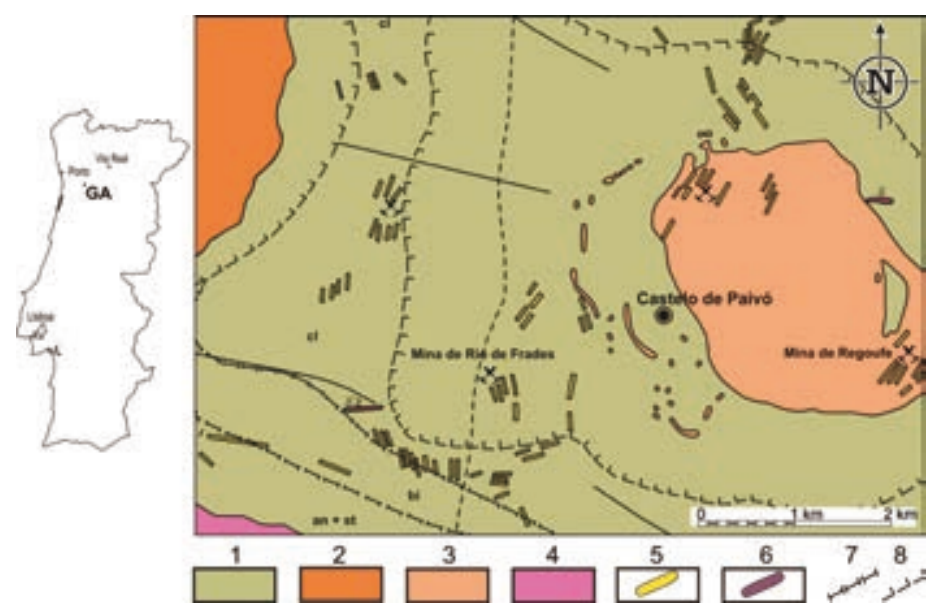

Fig. 1 - Localização geográfica do Geoparque Arouca (GA) e enquadramento geológico das minas de Regoufe e de Rio de Frades (adaptado da Folha 10-D, Oliveira de Azeméis, da Carta Geológica de Portugal). 1 - Super Grupo Dúrico-Beirão; 2 - Quartzodiorito biotítico (Maciço de Arouca); 3 - Granito de Regoufe; 4 - Granito da Serra de Freita; 5 - Filóes de quartzo; 6 - Doleritos $(\delta)$ e rochas básicas anfibolitizadas $\left(\delta^{\prime} z\right)$; 7 - Isógrada de metamorfismo regional; 8 - Isógrada de metamorfismo de contacto.

\section{3 - Drenagem ácida de minas}

Trabalhos anteriores (FAVAS, 2008; FAVAS et al., 2010) realizados na área das minas de Regoufe e de Rio de Frades, permitiram demonstrar a ocorrência de águas ácidas nestes locais. Estes efluentes, provenientes das galerias e das escombreiras, apresentam características químicas que refletem os processos de lixiviação de rochas mineralizadas com sulfuretos, caracterizando-se por apresentarem baixos valores de $\mathrm{pH}$ e altas concentraçóes de sulfato, arsénio e de metais em soluçáo.

Depois do início da atividade extrativa, uma grande quantidade de sulfuretos fica exposta às condiçôes superficiais, tendendo a desintegrar-se quimicamente e formam-se novos compostos, até que se restabeleça o equilíbrio com o meio (e.g., BANKS et al., 1997; VALENTE \& GOMES, 2009). Desta forma, os sulfuretos ficam expostos à ação conjunta do oxigénio, da água superficial e subterrânea e de bactérias oxidantes catalisadoras, ocorrendo uma série de reaçóes químicas de que resultam ácidos e outros compostos químicos, constituindo a denominada drenagem ácida de minas (DAM). No caso da arsenopirite, que é o sulfureto dominante das minas estudadas, a reação pode ser a seguinte (BUNDSCHUH et al., 2008):

$$
4 \mathrm{FeAsS}+13 \mathrm{O}_{2}+6 \mathrm{H}_{2} \mathrm{O} \rightarrow 4 \mathrm{Fe}^{2+}+4 \mathrm{SO}_{4}^{2-}+\mathrm{AsO}_{4}^{3-}+12 \mathrm{H}^{+}
$$

Portanto, os produtos da alteração de sulfuretos são ióes metálicos/semimetálicos em solução ou na forma de compostos estáveis e insolúveis em condiçóes superficiais, ião sulfato (pela conversão do enxofre) e soluçóes ácidas.

Estas águas ácidas provenientes da drenagem de uma mina, embora aparentemente límpidas, podem produzir uma série de situações de impacto negativo ao misturarem-se 
com águas naturais, havendo alteração na qualidade das águas e, consequentemente, efeitos nefastos sobre a manutenção do ecossistema fluvial circundante (e.g., BANKS et al., 1997; FAVAS \& CONDE, 2000; VALENTE \& GOMES, 2009; FAVAS et al., 2012).

\section{4- Metodologia}

Para a realização deste trabalho efetuaram-se duas campanhas de amostragem, tendo a $1^{\text {a }}$ sido realizada em setembro e correspondendo, por isso, ao período seco e a $2^{\mathrm{a}}$, aconteceu em abril, sendo representativa do período húmido. Na primeira campanha recolheram-se 13 amostras, tendo este número subido para 16 no decurso da $2^{\text {a }}$ campanha de amostragem (Fig. 2). Para a caracterização dos efluentes mineiros foram recolhidas amostras à saída de galerias e em zonas de escorrência mineira, correspondendo às estaçóes DAM1, DAM2, DAM3 e DAM4 em Regoufe e DAM5, DAM6 e DAM7 em Rio de Frades, sendo que as duas últimas apenas foram recolhidas na $2^{\text {a }}$ campanha, uma vez que na $1^{\text {a }}$ os locais encontravam-se secos. Para avaliar o impacto ambiental dos efluentes mineiros no sistema fluvial da área, assim como a capacidade autodepuradora deste, foram amostrados 9 pontos ao longo das principais linhas de água (LA 1-9), sendo que a última também foi recolhida apenas na $2^{\text {a }}$ campanha.

Foram determinados, in situ, os parâmetros de condutividade elétrica (CE), pH e temperatura, com recurso a medidores portáteis, e as espécies carbonatadas $\left(\mathrm{HCO}_{3}^{-}\right)$, por titulação. As análises laboratoriais foram realizadas no Laboratório de Química da UTAD, através dos seguintes métodos analíticos: Espetrometria de Absorção Atómica (EAA), para Ca, $\mathrm{Mg}, \mathrm{Na}$, $\mathrm{K}$ e Fe; EAA com câmara de grafite para $\mathrm{Mn}, \mathrm{Cu}, \mathrm{Zn}, \mathrm{Cd}, \mathrm{Co}, \mathrm{Ni}, \mathrm{Pb}$ e As; cromatografia aniónica de elevada eficiência (HPAEC) para $\mathrm{Cl}, \mathrm{F}, \mathrm{Br}, \mathrm{NO}_{2}, \mathrm{NO}_{3}, \mathrm{PO}_{4} \mathrm{e} \mathrm{SO}_{4}$.

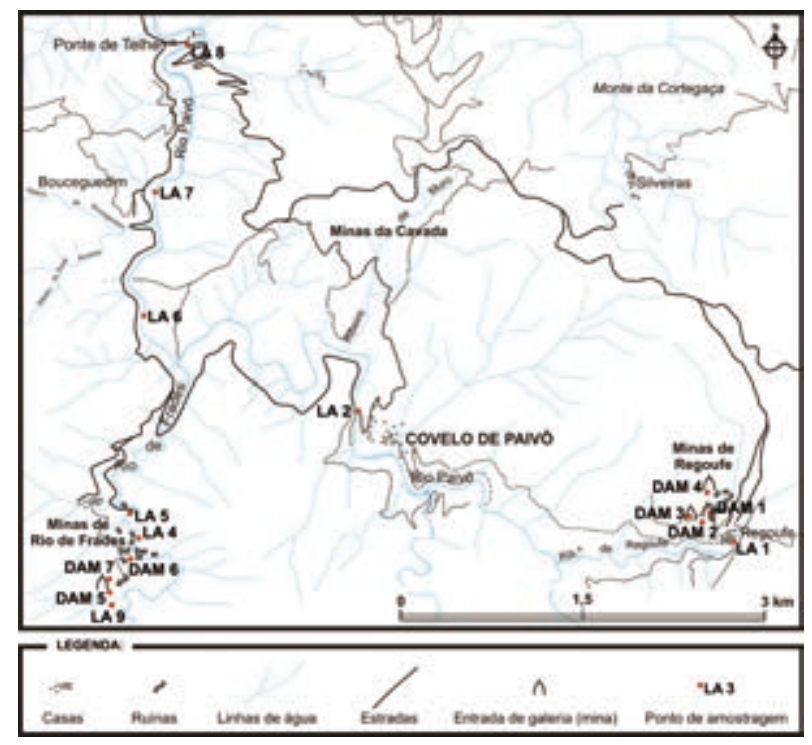

Fig. 2 - Mapa da área em estudo onde se encontram assinaladas as estaçôes de amostragem, assim como as principais localidades e linhas de água. 


\section{5 - Resultados e discussão}

Apresentam-se nas tabelas 1 e 2 os resultados analíticos obtidos na $1^{\text {a }}$ e na $2^{\text {a }}$ campanhas, respetivamente. Pela análise da tabela 1 , podemos verificar que as amostras DAM possuem valores de $\mathrm{pH}$ baixos $(4,26-6,46)$, quando comparados com as amostras LA. Os valores de condutividade elétrica são relativamente mais elevados nas amostras DAM. As concentraçôes de sulfato, na generalidade das amostras, são mais baixas do que o esperado, quando comparadas com os valores obtidos no trabalho realizado na área por FAVAS (2008), mas verifica-se que as concentraçôes nas amostras DAM são mais elevadas que as restantes amostras. Também se verifica a ocorrência de valores mais elevados de metais e metalóides em solução, principalmente no caso do Fe, Cd, Mn, Zn e As, com concentraçóes bastante mais elevadas nas DAM.

Analisando a tabela 2, verifica-se que na $2^{\text {a }}$ campanha, tal como na $1^{\text {a }}$, as amostras DAM distinguem-se das LA principalmente pelo $\mathrm{pH}$ ligeiramente mais baixo e concentraçóes de $\mathrm{SO}_{4}, \mathrm{Fe}, \mathrm{Cd}, \mathrm{Zn}, \mathrm{Mn}$ e As mais elevadas. Comparando os valores das duas campanhas, fica patente que o $\mathrm{pH}$ médio na $2^{\mathrm{a}}$ campanha é um pouco mais elevado e que as concentraçóes de vários elementos, incluindo o $\mathrm{SO}_{4}, \mathrm{Fe}, \mathrm{Cd}, \mathrm{Zn}, \mathrm{Mn}$ e As, são um pouco mais baixas do que na $1^{\mathrm{a}}$ campanha, refletindo a influência das variaçôes sazonais.

Observando o diagrama de Ficklin (Fig. 3), verifica-se que as amostras LA são classificadas como "pobres em metais" e "próximas da neutralidade", havendo apenas uma amostra pertencente à categoria "ácida”. As amostras DAM variam entre "ácidas" e "próximas da neutralidade" e pertencem ao patamar "pobre em metais", embora seja claro que a maioria destas amostras se aproxime do patamar "rica em metais". Por isso, é visível a distinção dos dois tipos de água, onde se destacam as amostras DAM1 e DAM2 (ambas da mina de Regoufe), que são as que possuem concentraçóes de metais mais elevadas, e as DAM2 e DAM5, que são as mais ácidas.

Tabela 1 - Resultados obtidos na $1^{\text {a }}$ campanha de amostragem $(n=13)$. Os valores a negrito representam os resultados superiores aos estipulados pela lei vigente relativamente à água para consumo humano (D.L. 306/2007 e D.L. 243/2001 ou D.L. 236/98).

\begin{tabular}{|l|c|c|ccc|cccccccccc|}
\cline { 2 - 2 } \multicolumn{1}{l|}{} & $(\mu \mathrm{S} / \mathrm{cm})$ & \multicolumn{9}{c|}{$\mathrm{mg} / \mathrm{L}$} & \multicolumn{10}{c|}{$\mu / \mathrm{L}$} \\
\hline amostra & $\mathrm{pH}$ & $\mathrm{C.E}$. & $\mathrm{HCO}_{3}$ & $\mathrm{SO}_{4}$ & $\mathrm{Mg}$ & $\mathrm{Fe}$ & $\mathrm{Cd}$ & $\mathrm{Pb}$ & $\mathrm{Cu}$ & $\mathrm{Co}$ & $\mathrm{Ni}$ & $\mathrm{Zn}$ & $\mathrm{Mn}$ & $\mathrm{As}$ \\
\hline sDAM1 & 6,00 & 32,6 & 3,55 & 5,56 & 0,40 & 62,00 & 13,31 & 0,49 & 1,10 & 4,60 & 1,20 & $\mathbf{6 8 0 , 0 0}$ & 104,90 & 236,80 \\
sDAM2 & 4,75 & 35,7 & 0,00 & 6,40 & 0,35 & 23,00 & 10,50 & 0,03 & 2,30 & 0,00 & 0,00 & 490,00 & 18,99 & 152,20 \\
sDAM3 & 6,46 & 24,1 & 3,36 & 2,57 & 0,24 & 32,00 & 2,97 & 0,24 & 2,40 & 0,00 & 0,00 & 120,00 & 7,75 & $\mathbf{6 3 , 4 4}$ \\
sDAM4 & 5,25 & 23,8 & 3,05 & 1,76 & 0,23 & 29,00 & 1,50 & 0,08 & 0,67 & 0,00 & 0,00 & 94,00 & 18,10 & 45,82 \\
sDAM5 & 4,29 & 42,9 & 0,00 & 10,60 & 0,65 & 321,00 & 0,26 & 0,00 & 3,80 & 0,06 & 5,81 & 51,44 & 42,47 & 3,40 \\
sLA1 & 5,35 & 36,6 & 3,05 & 5,38 & 0,80 & 50,00 & 1,10 & 0,46 & 0,97 & 0,00 & 1,10 & 44,00 & 10,86 & 14,97 \\
sLA2 & 5,81 & 26 & 3,66 & 3,12 & 0,46 & 44,00 & 0,04 & 0,15 & 0,41 & 0,00 & 0,32 & 82,80 & 3,30 & 5,60 \\
sLA3 & 5,67 & 21,4 & 3,36 & 2,04 & 0,35 & 44,00 & 0,07 & 0,00 & 1,30 & 0,00 & 0,55 & 52,36 & 5,97 & 3,20 \\
sLA4 & 5,70 & 23,7 & 3,66 & 3,12 & 0,40 & 47,00 & 0,06 & 0,00 & 0,80 & 0,00 & 0,72 & 10,61 & 7,64 & 3,30 \\
sLA5 & 6,22 & 26,3 & 2,75 & 5,62 & 0,51 & 35,00 & 0,12 & 0,00 & 0,69 & 0,00 & 1,30 & 11,44 & 15,04 & 4,10 \\
sLA6 & 6,42 & 26,7 & 3,05 & 3,53 & 0,49 & 65,00 & 0,02 & 0,00 & 1,20 & 0,00 & 0,94 & 45,57 & 7,86 & 9,10 \\
sLA7 & 6,47 & 26,7 & 3,97 & 4,19 & 0,49 & 50,00 & 0,03 & 0,00 & 1,30 & 0,00 & 1,10 & 14,83 & 8,32 & 8,10 \\
sLA8 & 6,44 & 27,4 & 3,36 & 4,18 & 0,52 & 53,00 & 0,02 & 0,00 & 1,20 & 0,00 & 0,73 & 22,57 & 7,89 & 11,37 \\
\hline
\end{tabular}


Tabela 2 - Resultados obtidos na $2^{\text {a }}$ campanha de amostragem $(n=16)$. Os valores a negrito representam os resultados superiores aos estipulados pela lei vigente relativamente à água para consumo humano (D.L. 306/2007 e D.L. 243/2001 ou D.L. 236/98).

\begin{tabular}{|l|c|c|ccc|cccccccccc|}
\multicolumn{1}{l|}{} & \multicolumn{1}{l|}{$(\mu \mathrm{S} / \mathrm{cm})$} & \multicolumn{3}{c|}{$\mathrm{mg} / \mathrm{L}$} & \multicolumn{10}{c|}{$\mathrm{gg} / \mathrm{L}$} \\
\hline amostra & $\mathrm{pH}$ & $\mathrm{C} . \mathrm{E}$. & $\mathrm{HCO}_{3}$ & $\mathrm{SO}_{4}$ & $\mathrm{Mg}$ & $\mathrm{Fe}$ & $\mathrm{Cd}$ & $\mathrm{Pb}$ & $\mathrm{Cu}$ & $\mathrm{Co}$ & $\mathrm{Ni}$ & $\mathrm{Zn}$ & $\mathrm{Mn}$ & $\mathrm{As}$ \\
\hline hDAM1 & 6,92 & 20,30 & 2,44 & 1,22 & 0,33 & 17,00 & 3,72 & 0,00 & 0,00 & 0,00 & 2,04 & 160,00 & 0,87 & 83,00 \\
hDAM2 & 5,54 & 24,60 & 1,83 & 2,85 & 0,21 & 20,00 & 4,69 & 0,00 & 0,00 & 0,00 & 3,53 & 170,00 & 5,09 & $\mathbf{6 3 , 0 0}$ \\
hDAM3 & 7,50 & 19,10 & 3,05 & 1,26 & 0,18 & 14,00 & 1,25 & 0,00 & 0,00 & 0,00 & 1,79 & 50,00 & 0,91 & 36,34 \\
hDAM4 & 5,80 & 22,60 & 2,44 & 1,16 & 0,20 & 3,00 & 1,25 & 0,00 & 2,18 & 0,00 & 1,79 & 30,00 & 4,48 & 31,10 \\
hDAM5 & 4,76 & 46,50 & 0,00 & 9,80 & 0,72 & 109,00 & 0,00 & 0,00 & 0,00 & 2,62 & 2,04 & 0,00 & 18,94 & 1,65 \\
hDAM6 & 4,60 & 58,20 & 0,00 & 16,46 & 1,27 & 218,00 & 0,00 & 0,00 & 0,97 & 4,19 & 0,00 & 30,00 & 0,05 & 3,96 \\
hDAM7 & 6,32 & 21,80 & 2,75 & 2,36 & 0,43 & 54,00 & 0,00 & 0,00 & 1,41 & 0,00 & 0,00 & 0,00 & 0,05 & 0,76 \\
hLA1 & 5,99 & 25,70 & 2,75 & 2,22 & 0,49 & 14,00 & 1,25 & 0,00 & 0,00 & 0,08 & 1,79 & 0,00 & 3,28 & 10,13 \\
hLA2 & 7,10 & 20,70 & 3,66 & 1,64 & 0,39 & 14,00 & 1,25 & 0,00 & 0,38 & 0,07 & 1,79 & 0,00 & 1,17 & 2,43 \\
hLA3 & 6,50 & 21,20 & 3,36 & 1,65 & 0,38 & 34,00 & 0,00 & 0,00 & 0,11 & 0,37 & 2,54 & 0,00 & 2,93 & 0,89 \\
hLA4 & 6,82 & 21,40 & 2,14 & 1,80 & 0,40 & 20,00 & 0,00 & 0,00 & 2,02 & 0,47 & 0,00 & 0,00 & 3,05 & 0,92 \\
hLA5 & 5,79 & 25,30 & 1,83 & 3,62 & 0,52 & 17,00 & 0,00 & 0,00 & 0,56 & 0,52 & 0,00 & 0,00 & 7,33 & 10,02 \\
hLA6 & 6,80 & 22,20 & 2,44 & 2,40 & 0,47 & 100,00 & 0,00 & 2,50 & 3,97 & 0,56 & 0,00 & 0,00 & 7,33 & 3,18 \\
hLA7 & 6,70 & 23,40 & 3,05 & 2,32 & 0,48 & 37,00 & 0,00 & 0,00 & 0,68 & 0,19 & 0,00 & 0,00 & 0,92 & 2,81 \\
hLA8 & 6,70 & 23,20 & 3,05 & 2,47 & 0,49 & 60,18 & 0,00 & 2,50 & 5,64 & 0,69 & 0,00 & 0,00 & 4,32 & 9,76 \\
hLA9 & 6,30 & 20,70 & 2,14 & 1,52 & 0,37 & 34,00 & 0,00 & 0,00 & 0,00 & 0,00 & 0,00 & 0,00 & 0,05 & 0,85 \\
\hline
\end{tabular}

Pela análise da figura 3 b), relativa à $2^{\text {a }}$ campanha, verifica-se que todas as amostras são "pobres em metais", embora a maioria das DAM possua valores mais elevados em metais, com exceção da amostra DAM7. Pela análise deste gráfico, está bem patente a diminuição das concentrações de metais, comparativamente com a $1^{\text {a }}$ campanha, embora não se tenha alterado a sua classificação. Portanto, a classificação e separação das duas tipologias de água é semelhante nas duas campanhas de amostragem, em que se verifica a tendência das DAM para valores de $\mathrm{pH}$ mais baixos e concentrações em metais elevadas, comparativamente com as amostras LA.

Nas Figs. 4, 5 e 6 apresentam-se os gráficos que relacionam as concentraçóes de $\mathrm{SO}_{4}$ com os valores de $\mathrm{pH}$, de condutividade e com o somatório das concentraçóes de $\mathrm{Fe}$, $\mathrm{Cu}$ e $\mathrm{Zn}$. Analisando os diagramas da $1^{\mathrm{a}}$ campanha, podemos distinguir as duas tipologias de água em estudo, principalmente pelo acréscimo das concentraçôes de $\mathrm{SO}_{4}$ e dos metais em solução, com maior clareza nas amostras DAM1, DAM2 e DAM5. Também se verifica em algumas amostras DAM a condutividade ligeiramente mais elevada (DAM5) e pH mais baixo (DAM5 e DAM2), comparativamente com as amostras LA.

Analisando os diagramas da 2a campanha, verifica-se que as amostras DAM5 e DAM6 se destacam das restantes, nomeadamente no que se refere ao ião $\mathrm{SO}_{4}{ }^{2-}$. Considerando o somatório das concentraçóes de Fe, $\mathrm{Cu}$ e $\mathrm{Zn}$, verifica-se que as amostras DAM1 e DAM2 também se separam das restantes. Consultando os resultados obtidos, apurámos que o Zn é o principal responsável pela separação destas amostras, enquanto o Fe determina o destacamento das amostras DAM5 e DAM6. Comparando estes resultados com os da $1^{\text {a }}$ 
campanha, podemos dizer que, apesar de na $2^{\text {a }}$ campanha as concentraçóes serem mais baixas, não se evidenciam diferenças na composição iónica das amostras recolhidas. As concentraçóes mais baixas, observadas na generalidade dos parâmetros nesta campanha, deverão estar relacionadas, maioritariamente, com o efeito de diluição característico do período húmido.

Foram detetados alguns valores anómalos de As em alguns pontos LA. No local de amostragem LA1 (povoação de Regoufe), em ambos os períodos, verificam-se níveis de As superiores a $10 \mu \mathrm{g} / \mathrm{L}$, que é o valor paramétrico de acordo com o Decreto-Lei no 306/2007, (período seco - 14,97 $\mu \mathrm{g} / \mathrm{L}$ e período húmido - 10,13 $\mu \mathrm{g} / \mathrm{L}$ ), talvez devido à influência das mineralizaçóes de Regoufe, por ser ainda um sítio próximo destas minas.

a)

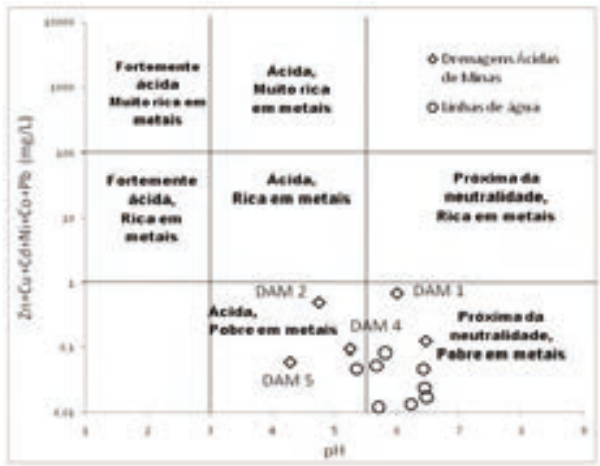

b)

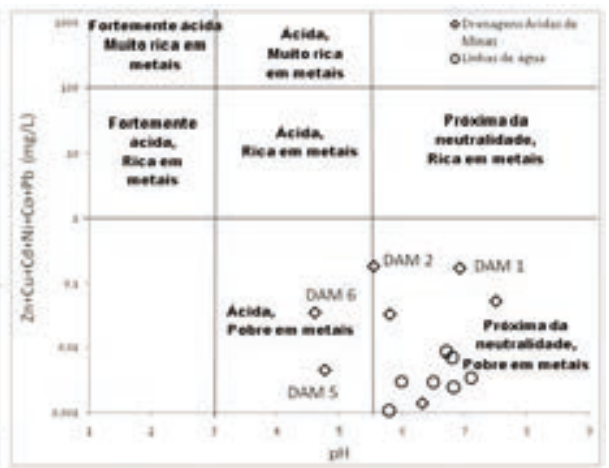

Fig. 3 - Classificação de FICKLIN et al. (1992) das amostras LA e DAM, recolhidas na $1^{\text {a }}$ (a) e na $2^{\text {a }}$ (b) campanhas de amostragem.

a)

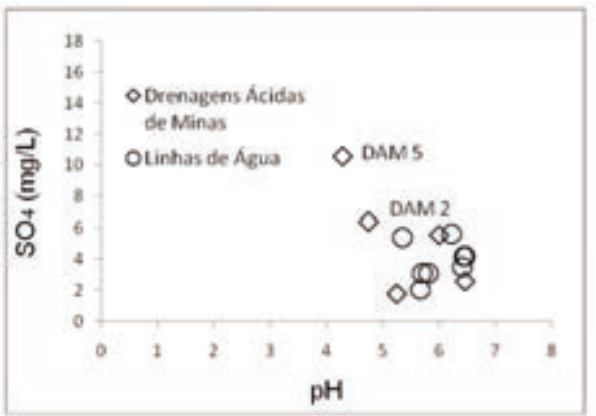

b)

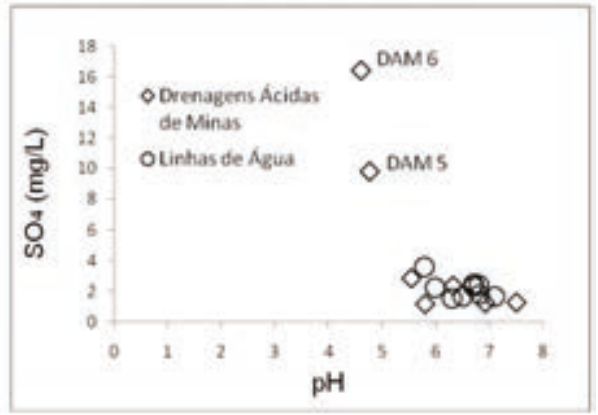

Fig. 4 - Diagramas SO4 vs pH das amostras LA e DAM da $1^{\text {a }}$ campanha (a) e $2^{\text {a }}$ campanha (b). 
a)

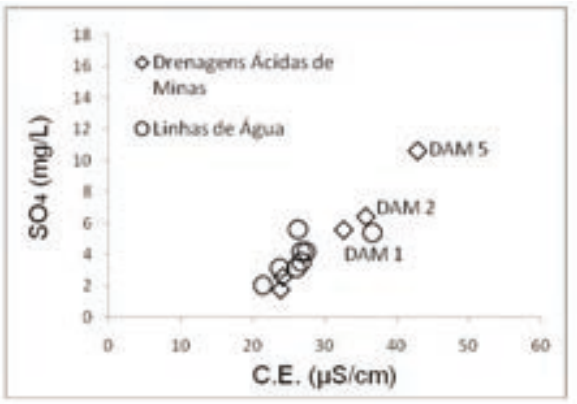

b)

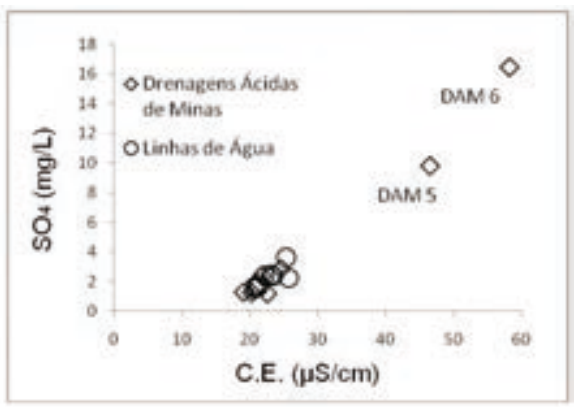

Fig. 5 - Diagramas SO4 vs condutividade (C.E.) das amostras LA e DAM da $1^{\text {a }}$ campanha (a) e $2^{\mathrm{a}}$ campanha (b).

a)

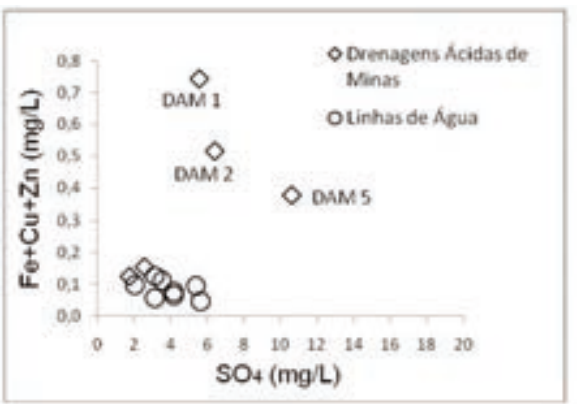

b)

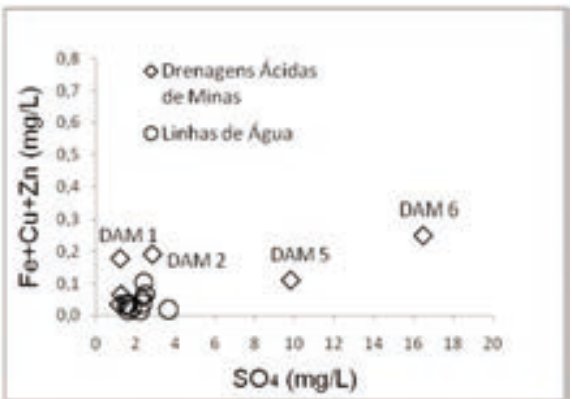

Fig. 6 - Diagramas SO4 vs $(\mathrm{Fe}+\mathrm{Cu}+\mathrm{Zn})$ das amostras LA e DAM da $1^{\text {a }}$ campanha (a) e $2^{\text {a }}$ campanha (b).

Também se observam valores de As desta ordem de grandeza em alguns pontos LA ao longo do Rio Paivô nos dois períodos, nomeadamente em Ponte de Telhe (LA8). Estes valores poderão dever-se à interferência das minas da Cavada e da Pena Amarela.

De referir também que, junto à lavaria e aos tanques do couto mineiro de Rio de Frades, ocorrem pequenos depósitos de concentrados de sulfuretos, resultantes da antiga lavaria da mina, onde se verificaram valores de As e Fe da ordem dos $100000 \mathrm{mg} / \mathrm{kg}$ (FAVAS, 2008) e também concentrações significativas de W, Cu, Pb e Mn apresentando, portanto, elevado risco de contaminaçáo ambiental, uma vez que estes depósitos se encontram expostos às condiçôes atmosféricas e aos processos erosivos.

\section{6 - Conclusốes}

Os resultados obtidos permitem agrupar as duas tipologias, LA e DAM, em função da tendência das segundas para registar valores de maior acidez e concentraçôes mais elevadas 
em metais e metalóides. A análise dos resultados demonstra também uma diferenciação em função da mineralização local. As amostras DAM de Regoufe destacam-se pelas concentraçóes elevadas em $\mathrm{Zn}$ e As (e menores em Fe e $\mathrm{SO}_{4}$ ), e as amostras DAM de Rio de Frades discriminam-se principalmente pelos valores elevados em $\mathrm{Fe}$ e $\mathrm{SO}_{4}$.

No que respeita ao estado atual e potencial de contaminaçáo destas minas abandonadas, as galerias e escombreiras das minas de Regoufe apresentam significativo potencial de contaminação hídrico, devido a elevadas concentraçóes em elementos tóxicos, nomeadamente em As e Cd. Por outro lado, no couto mineiro de Rio de Frades o maior problema ambiental assenta na existência de depósitos de concentrados de sulfuretos, resultantes da lavaria, expostos com implicaçôes graves na contaminação dos solos e vegetação envolventes. É, assim, urgente tratar e monitorizar linhas de água na zona de Regoufe, principalmente em relação ao As, e remover adequadamente os depósitos de sulfuretos da mina de Rio de Frades, de forma a mitigar os efeitos nefastos da contaminação destas minas.

Por fim, a eventual anomalia em As detetada nas amostras recolhidas junto à aldeia de Ponte de Telhe, justifica claramente a realização de estudos posteriores para averiguar a fonte deste elemento, determinar a intervençáo e o tratamento mais adequado, e a implementação de análises periódicas de monitorização destas concentraçôes.

\section{Referências Bibliográficas}

BANKS, D., YOUNGER, P. L., ARNESEN, R. T., IVERSEN, E. R. \& BANKS, S. B. (1997) - Mine-water chemistry: the good, the bad and the ugly. Environmental Geology, 32, p. 157-174.

BUNDSCHUH, J., GIMÉNEZ FORCADA, E., GUÉRÈQUIZ, R., PÉREZ CARRERA, A., GARCIA, M. E., MELLO, J. \& DESCHAMPS, E. (2008) - Fuentes geogénicas de arsénico y su libéración al médio ambiente. In: Bundschuh, A., Pérez Carrera, A. \& Litter, M.I. (eds.) Distribuición del arsénico enlas regiones Ibérica e Iberoamericana, CYTED, Argentina, $230 \mathrm{p}$.

FAVAS, P. J. C. (2008) - Biogeoquímica em áreas mineiras estano-volframíticas. Tese de Doutoramento. Universidade de Trás-os-Montes e Alto Douro, Vila Real, 805 p.

FAVAS, P. \& CONDE, L. E. N. (2000) - Impacte de uma mina abandonada na qualidade das águas superficiais: o exemplo das Minas de Vale das Gatas (Sabrosa - Vila Real). Recursos Hidricos, 21, p. 31-45.

FAVAS, P., PRATAS, J. \& GOMES, E. (2010) - Hidroquímica das águas superficiais na área mineira de Regoufe (Arouca, Norte de Portugal). Resumos do VIII Congresso Nacional de Geologia-e-Terra Revista Electrónica de Ciências da Terra, 13. http://e-terra.geopor.pt (consultado em 2011.09.08).

FAVAS, P., PRATAS, J. \& GOMES, E. (2012) - Hydrochemistry of superficial waters in the Adoria mine area (Northern Portugal): environmental implications. Environmental Earth Sciences, 65, p. 363-372.

FICKLIN, W. H., PLUMLEE, G. S., SMITH, K. S. \& MCHUGH, J. B. (1992) - Geochemical classification of mine drainages and natural drainages in mineralized areas. In: Kharaka \& Maest eds.). Water-Rock Interaction, 1, Low Temperature Environments, Balkema, p. 381-384.

SLUIJK, D. (1963) - Geology and tin-tungsten deposits of the Regoufe área, Northern Portugal. Doctoral Thesis, Universitei van Amsterdam, 123 p.

VALENTE, M.T. \& GOMES, L. C. (2009) - Occurrence, properties and pollution potential of environmental minerals in acid mine drainage. Science of the Total Environment, p. 1135-1152. 